\title{
NodFE-Dependent Fatty Acids That Lack an $\alpha-\beta$ Unsaturation Are Subject to Differential Transfer, Leading to Novel Phospholipids
}

\author{
Otto Geiger, ${ }^{1}$ John Glushka, ${ }^{2}$ Ben J. J. Lugtenberg, ${ }^{1}$ Herman P. Spaink, ${ }^{1}$ and Jane E. Thomas-Oates ${ }^{3}$ \\ ${ }^{1}$ Institute of Molecular Plant Sciences, Leiden University, Leiden, The Netherlands; ${ }^{2}$ Complex Carbohydrate \\ Research Center, 220 Riverbend Road, Athens, GA 30602, U.S.A.; ${ }^{3}$ Bijvoet Center for Biomolecular Re- \\ search, Department of Mass Spectrometry, Utrecht University, Sorbonnelaan 16, 3584 CA Utrecht, The \\ Netherlands \\ Accepted 23 September 1997.
}

In Rhizobium leguminosarum, the nodABC and nodFEL operons are involved in the production of lipo-chitin oligosaccharide signals that mediate host specificity. A nodFE-determined, highly unsaturated C18:4 fatty acid (trans-2, trans-4, trans-6, cis-11-octadecatetraenoic acid) is essential for the ability of the signals to induce nodule meristems and pre-infection thread structures on the host plant Vicia sativa. Of the nod genes, induction of only $\operatorname{nodFE}$ is sufficient to modify fatty acid biosynthesis to yield trans-2, trans-4, trans-6, cis-11-octadecatetraenoic acid, with an absorbance maximum of 303 nm. This unusual C18:4 fatty acid is not only found in the lipo-chitin oligosaccharides but is also associated with the phospholipids (O. Geiger, J. E. Thomas-Oates, J. Glushka, H. P. Spaink, and B. J. J. Lugtenberg, 1994, J. Biol. Chem. 269:11090-11097). Here we report that the phospholipids can contain other nodFE-derived fatty acids, a C18:3 trans-4, trans-6, cis-11-octadecatrienoic acid that has a characteristic absorption maximum at $225 \mathrm{~nm}$, and a C18:2 octadecadienoic acid. Neither this C18:3 nor this C18:2 fatty acid has to date been observed attached to lipo-chitin oligosaccharides, suggesting that an as yet unknown acyl transferase (presumably $\operatorname{Nod} A$ ), responsible for the transfer of the fatty acyl chain to the glycan backbone of the lipo-chitin oligosaccharides, does not transfer all fatty acids synthesized by the action of NodFE to the lipo-chitin oligosaccharides. Rather, it must have a preference for $\alpha-\beta$ unsaturated fatty acids during transfer.

Rhizobium bacteria interact with leguminous plants in a host-specific manner and can cause the formation of nitrogenfixing root nodules. Plant-specific flavonoids induce rhizobial

Corresponding author: Otto Geiger

E-mail: geig1332@mailszrz.zrz.tu-berlin.de

Present address of O. Geiger: Technische Universität Berlin, Institut für Biotechnologie, FG Technische Biochemie, Seestraße 13, 13353 Berlin, Germany. nod genes needed for nodulation. In Rhizobium leguminosarum, the nodABC and nodFEL operons are involved in the production of lipo-chitin oligosaccharide (LCO) signal molecules that mediate host specificity. A nodL-determined $O$-acetyl substituent and a nodFE-determined, highly unsaturated C18:4 fatty acid (trans-2, trans-4, trans-6, cis-11octadecatetraenoic acid) are both essential for the ability of the signals to induce nodule meristems (Spaink et al. 1991) and pre-infection thread structures (van Brussel et al. 1992) on the host plant Vicia sativa.

We now focus on the question as to how these LCO signals are synthesized in Rhizobium. For the synthesis of a basic LCO, active nodABC genes are required (Spaink et al. 1991). During biosynthesis the NodC protein seems to function as a glycosyl transferase producing chitin oligosaccharides (Geremia et al. 1994; Kamst et al. 1995). Purified NodB protein shows $\mathrm{N}$-deacetylase activity and removes an $\mathrm{N}$-acetyl group from the $N$-acetyl glucosamine of the nonreducing terminal residue of chitin oligosaccharides (John et al. 1993). Finally, the NodA protein is involved in the transfer of a fatty acyl residue to the free amino group of the chitooligosaccharide backbone (Atkinson et al. 1994; Röhrig et al. 1994). Recently, it has even been demonstrated that NodA, which was formerly considered to be the product of a common nod gene, can function as a host-specific determinant during the transfer of fatty acids in LCO biosynthesis (Debellé et al. 1996; Ritsema et al. 1996; Roche et al. 1996).

Here, we report the results of our study of the biosynthesis and transfer of the unusual nodFE-derived fatty acyl residues. Of the nod genes, induction of nodFE alone is sufficient for the synthesis of the host-specific $303 \mathrm{~nm}$-absorbing trans-2, trans-4, trans-6, cis-11-octadecatetraenoic acid (C18:4) (Geiger et al. 1994), which in $R$. leguminosarum bv. viciae is the only nodFE-derived fatty acid transferred in the formation of host-specific, mitogenic LCO signal molecules (Spaink et al. 1991). Here we show that two other nodFE-derived fatty acyl residues, a $225 \mathrm{~nm}$-absorbing trans-4, trans-6, cis-11octadecatrienoic acid (C18:3) and an octadecadienoic acid (C18:2), are formed, although they are not incorporated into LCOs in R. leguminosarum and can only be detected in membrane phospholipids. 


\section{RESULTS}

\section{Lipid extracts contain several nodFE-dependent fatty acids.}

During our search for metabolites produced by the nodFE gene products, we observed that NodFE are sufficient to redirect fatty acid biosynthesis in Rhizobium in order to obtain an unusual C18:4 fatty acid. This $303 \mathrm{~nm}$-absorbing fatty acid was found to be an important structural element of the hostspecific LCOs of $R$. leguminosarum bv. viciae (Spaink et al. 1991), but it was also detected linked to the $s n-2$ position of phosphatidylcholine (Geiger et al. 1994). We had also noticed that other phospholipids showed an absorbance maximum at $225 \mathrm{~nm}$ and that they were also formed only after the induction of the nodFE genes (Geiger et al. 1994). A $225 \mathrm{~nm}-$ absorbance maximum is consistent with species bearing two conjugated double bonds, suggesting to us that, in addition to the $303 \mathrm{~nm}$-absorbing C18:4 fatty acid, in which three trans double bonds are in conjugation with the carbonyl group, the phospholipids may alternatively bear different nodFE-dependent fatty acyl groups.

We therefore analyzed the fatty acid composition of crude lipid extracts obtained from $R$. leguminosarum LPR5045.pMP280.pMP1255, a strain that is able to overexpress the genes nodFE in the presence of the flavonoid inducer naringenin (Geiger et al. 1994). Figure 1 shows gas chromatograms of methyl ester derivatives obtained from lipid extracts from a noninduced (Fig. 1A) and a naringenininduced (Fig. 1B) bacterial cell suspension. The major fatty acid methyl ester present in the preparations obtained under both experimental conditions is that of cis-vaccenic acid, which is known to be the predominant fatty acid in R. legumi-

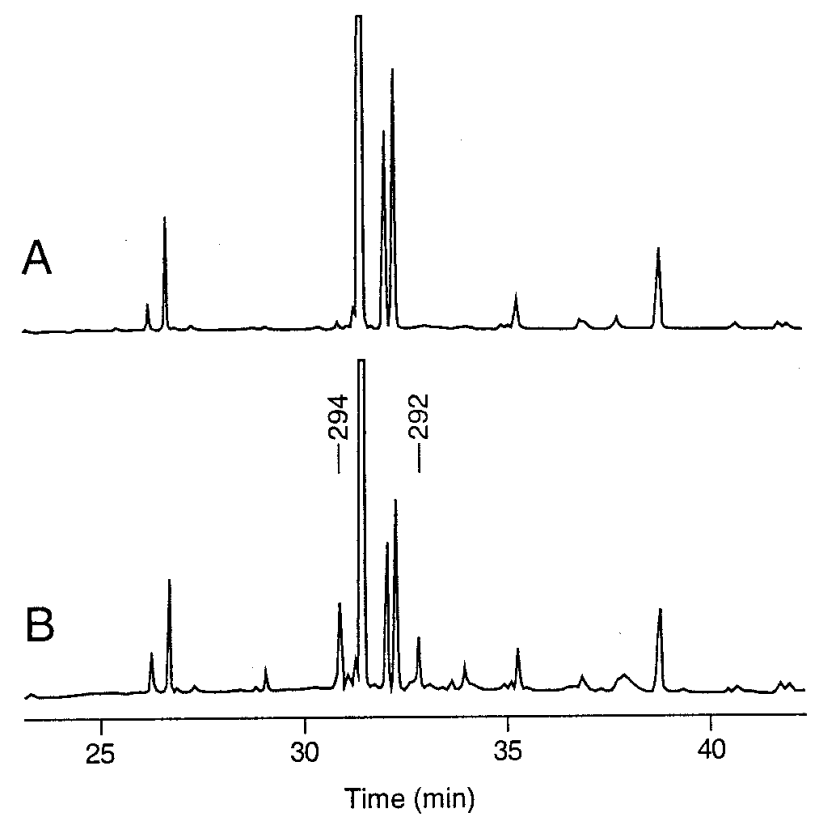

Fig. 1. Gas chromatographic separation of methyl esters obtained from (A) uninduced and (B) nodFE-induced lipid extracts from Rhizobium leguminosarum LPR5045.pMP280.pMP1255. Detection was performed with a flame ionization detector. In the nodFE-induced situation, two novel substances are indicated by their masses for the molecular ions at $\mathrm{m} / z, 294$ and 292, respectively, when analyzed in a mass spectrometer. nosarum and which has a retention time of $31.4 \mathrm{~min}$. In addition, two peaks with retention times of 30.9 and $32.6 \mathrm{~min}$ are only present when nodFE have been induced (Fig. 1B). If the gas chromagraph is linked to a mass spectrometer (with electron ionization) the two peaks with retention times of 30.9 and 32.6 min give $\mathbf{M}^{+}$molecular ions at $\mathrm{m} / z, 294$ and $\mathrm{m} / \mathrm{z}$, 292, respectively. These masses are consistent with methyl esters of C18:2 and C18:3 fatty acids. A fragment ion is observed at $\mathrm{m} / \mathrm{z}, 74$ in the spectrum of both compounds, corresponding to a McLafferty rearrangement ion (data not shown) indicative of fatty acid methyl esters. In the case of flame ionization detection, the peak area of the substance with a retention time of $30.9 \mathrm{~min}$ is substantially larger than that of the substance eluting at $32.6 \mathrm{~min}$, suggesting that there is significantly more methyl ester of the C18:2 than of the C18:3 fatty acid present. Two-dimensional, thin-layer chromatographic separation into the individual phospholipid classes and their gas chromatographic (GC) analysis after transmethylation indicated that the $\mathrm{C} 18: 2$ (retention time $30.9 \mathrm{~min}$ ) and the $\mathrm{C} 18: 3$ (retention time $32.6 \mathrm{~min}$ ) fatty acids were associated with the different classes of phospholipids (data not shown). Minor peaks with retention times of 30.9 and $32.6 \mathrm{~min}$, showing $\mathrm{M}^{+}$molecular ions at $m / z 294$ and $m / z$ 292, respectively, were also detected in methanolyzed lipid extract of flavonoid-induced $R$. leguminosarum bv. viciae RBL5560 wild type (data not shown), suggesting that both nodFE-related substances are formed when the nodFE genes are expressed at wild-type levels. These results are surprising and seem to contradict our earlier finding that the nodFE genes are responsible for the synthesis of a C18:4 fatty acid that can be linked to the phospholipids (Geiger et al. 1994).

\section{Purification of nodFE-dependent phospholipids.}

In order to understand which fatty acids are synthesized by the action of NodFE from $R$. leguminosarum bv. viciae, we decided to purify several nodFE-dependent phospholipids and determine their covalent structures.

Chloroform phases of Bligh-Dyer extracts were chromatographed on DEAE-cellulose, which allowed separation of the neutral phospholipids (phosphatidylethanolamine, PE; monomethylphosphatidylethanolamine, MMPE; dimethylphosphatidylethanolamine, DMPE; and phosphatidylcholine, PC) from anionic phospholipids (phosphatidylglycerol, PG; and cardiolipin, CL). The neutral phospholipid fraction eluted with chloroform/methanol (9:1, vol/vol) whereas the anionic phospholipids were detected in the chloroform/methanol (4:1, $\mathrm{vol} / \mathrm{vol}$ ) eluate containing $50 \mathrm{mM}$ ammonium acetate. Neutral and anionic fractions were further separated with normal phase high-pressure liquid chromatography (HPLC) on silica gel, which allows separation based mainly on the structures of the head groups. Under these conditions, phosphatidylcholine (in the neutral fraction) is bound strongly to the column, elutes at a retention time of 34 to $40 \mathrm{~min}$, and can therefore be totally separated from all other phospholipid classes. The phosphatidylcholine fraction was further subjected to reverse phase HPLC, allowing base line separation of $303 \mathrm{~nm}$-absorbing phosphatidylcholine (retention time of 131 to $148 \mathrm{~min}$ ) from $225 \mathrm{~nm}$-absorbing phosphatidylcholine (retention time of 150 to $170 \mathrm{~min}$ ) (Fig. 2).

A second class of substances found in the neutral fraction, monomethylphosphatidylethanolamine (MMPE), elutes with a 
retention time of 15 to 17 min during normal phase HPLC. In a final purification step (reverse phase HPLC) the $303 \mathrm{~nm}-$ absorbing MMPE (retention time of 124 to $132 \mathrm{~min}$ ) and the $225 \mathrm{~nm}$-absorbing MMPE (retention time of 135 to $152 \mathrm{~min}$ ) could be separated, yielding nearly homogenous preparations.

Separation of the anionic fraction with normal phase HPLC yielded phosphatidylglycerol (PG) with a retention time of 8 to $9 \mathrm{~min}$. In a subsequent purification step (reverse phase HPLC) the $303 \mathrm{~nm}$-absorbing PG (retention time of 38 to 42 $\mathrm{min}$ ) and the $225 \mathrm{~nm}$-absorbing PG (retention time of 44 to 49 min) could be separated.

Purified $303 \mathrm{~nm}$-absorbing phospholipids showed absorbance ratios $A_{303} / A_{206}=5.0$ to 7.0 depending on the phospholipid species and the solvent used. Purified $225 \mathrm{~nm}-$ absorbing phospholipids showed absorbance ratios $A_{225} / A_{206}=$ 2.0 to 2.4 depending on the phospholipid species and the solvent used. These data suggest that the molar absorptivity of $303 \mathrm{~nm}$-absorbing phospholipids at $303 \mathrm{~nm}$ is at least twice that of $225 \mathrm{~nm}$-absorbing phospholipids at $225 \mathrm{~nm}$.

\section{Chemical structure of $\mathbf{2 2 5} \mathbf{n m}$-absorbing phosphatidylcholine.}

The purified $225 \mathrm{~nm}$-absorbing phosphatidylcholine was analyzed by 2 - and 4-sector mass spectrometric (MS) methods in both the positive and the negative ion modes.

The positive ion fast atom bombardment-mass spectrum (FAB-MS) contained an intense $\mathbf{M}^{+}$molecular ion at $m / z, 782$ and two somewhat less intense $\mathbf{M}^{+}$molecular ions at $m / z, 784$ and 758 , which are accompanied by thioglycerol adduct ions at $m / z 890,892$, and 866 consistent with the presence of unsaturated fatty acids (Fukuda et al. 1985). Positive collision-induced-dissociation tandem mass spectrometry (CID MS-MS) analysis of these three $\mathrm{M}^{+}$ions yielded spectra all containing the same, intense product ion at $\mathrm{m} / \mathrm{z} 184$, corresponding to the choline phosphate head group $\left(\mathrm{N}^{+}\left(\mathrm{CH}_{3}\right)_{3}{ }^{-}\right.$ $\left.\mathrm{CH}_{2} \mathrm{CH}_{2}-\mathrm{PO}_{2}(\mathrm{OH})_{2}\right)$, which ion is diagnostic for phosphatidylcholine phospholipids (Hiyashi et al. 1989). The species giving rise to the ion at $\mathrm{m} / \mathrm{z} 782$ thus corresponds to a phosphatidylcholine containing fatty acyl chains with a total of 36 carbon atoms and four double bonds, while that giving the ion at $m / z, 784$ probably derives from a related impurity with one

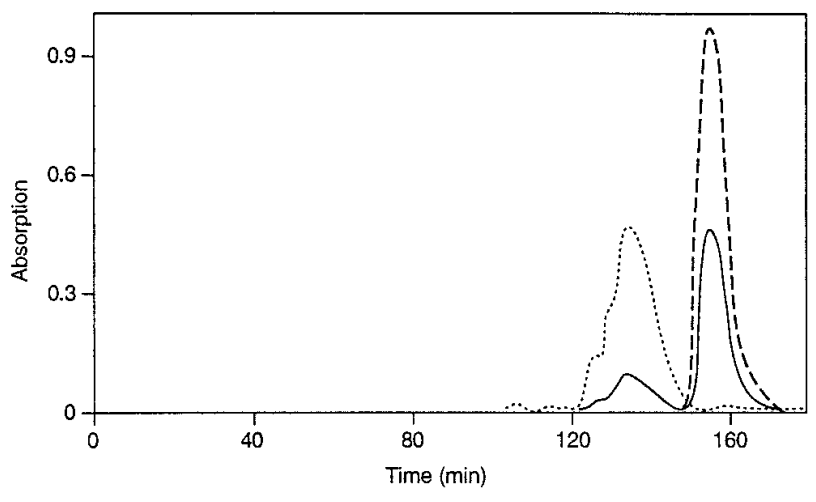

Fig. 2. Separation of $225 \mathrm{~nm}$-absorbing phosphatidylcholine (PC) from 303 nm-absorbing PC with high-pressure liquid chromatography (HPLC) on reverse phase silica gel. The PC fraction, as obtained after chromatography on silica gel, was separated into molecular species as detailed in Materials and Methods. Absorptions at 206 (solid line), 225 (dashed line), and 303 (dotted line) nm are indicated. fewer double bond. The compound giving the ion at $\mathrm{m} / \mathrm{z}, 758$ corresponds to a phosphatidylcholine with a total of 34 carbon atoms and two double bonds.

In order to determine the fatty acyl chains present and their sites of esterification to the glycerol, the same negative ion CID method was used as proved successful in making these assignments for the $303 \mathrm{~nm}$-absorbing phosphatidylcholine (Geiger et al. 1994). This involves collisional activation of the negative ion generated on loss of the choline head group, and examination of the relative intensities of the resulting product ions. The ion generated on elimination of the $s n-2$ fatty acid is always more intense than that generated by the analogous $s n-1$ elimination (Huang et al. 1992). Consequently, the negative ion at $m / z, 695$ (corresponding to $[\mathrm{M}-\text { choline }]^{-}$for the species giving $\mathrm{M}^{+}$at $\mathrm{m} / \mathrm{z}$ 782) was subjected to CID MS-MS analysis. The resulting spectrum contained two sets of ions. Those at $m / z 277$ and 281 represent carboxylate anions for $\mathrm{C} 18: 3$ and $\mathrm{C} 18: 1$ fatty acids, respectively, while those at $m / z, 417$ and 413 arise on elimination of a C18:3 and a C18:1 fatty acid from the parent ion, respectively. Since the ion at $m / z 417$ is significantly more intense than that at $m / z 413$, it can be concluded that the unusual C18:3 fatty acid is located at $s n-2$, while the $s n-1$ position bears the commonly occurring C18:1 fatty acid.

The ${ }^{1} \mathrm{H}$ nuclear magnetic resonance (NMR) spectra of the $225 \mathrm{~nm}$-absorbing PC showed resonances and coupling patterns expected for acyl side chains containing double bonds. In particular, the two-dimensional, double-quantum-filtered proton-proton correlated (DQFCOSY) spectrum (Fig. 3) revealed four signals between $\delta 5.3$ and $\delta 5.9$ that correspond to methine protons from conjugated double bonds in positions 4 to 7 of one of the acyl chains. The figure indicates their connectivity to the upfield signals of the methylene protons $(\delta 2.4$ to $\delta 1.2$ ) in the fatty acid chain. The $225 \mathrm{~nm}$-absorbing PC contains the $\mathrm{C} 18: 3$ fatty acid, where the two conjugated double bonds are both in trans (E-E) configuration. This is confirmed by the proton coupling constants across the bonds of 14.5 Hz. These results are similar to those found for the acyl chain of the $303 \mathrm{~nm}$-absorbing PC and the acyl chain of mitogenic LCOs from R. leguminosarum bv. viciae (Geiger et al. 1994; Spaink et al. 1991). However, the chemical shifts of protons from positions 2 and $3(\delta 2.30, \delta 2.23)$ clearly indicate saturated methylene groups. Additional signals at $\delta 5.2$ are due to the isolated double bonds in both chains at position 11 and 12, and resonances belonging to the phosphatidylcholine group are also indicated (c1 to c5 in Figure 3). The spectrum also shows signals due to some unidentified contaminants.

From the MS and the NMR spectroscopic studies we conclude that the $225 \mathrm{~nm}$-absorbing phosphatidylcholine has the primary chemical structure presented in Figure 4.

\section{Chemical structures of nodFE-dependent monomethylphosphatidyl ethanolamines and phosphatidylglycerols.}

The purified $303 \mathrm{~nm}$ - and $225 \mathrm{~nm}$-absorbing monomethylphosphatidyl ethanolamine and phosphatidylglycerol fractions were analyzed by 2- and 4-sector MS methods in both the positive and the negative ion modes. The results of the analyses and the tentative structural assignments are summarized in Table 1 .

The fraction containing the $303 \mathrm{~nm}$-absorbing MMPE contained three different MMPE molecular species having 
$[\mathrm{M}+\mathrm{H}]^{+}$pseudomolecular ions at $\mathrm{m} / \mathrm{z}, 704, \mathrm{~m} / \mathrm{z} 730$ (most intense), and $\mathrm{m} / \mathrm{z} 752$ that co-migrated through all purification procedures. These pseudomolecular ions were accompanied by a thioglycerol adduct ion at $m / z, 812,838$, and 860 , respectively. These three molecular species were represented by corresponding $[\mathrm{M}-\mathrm{H}]^{-}$pseudomolecular ions at $\mathrm{m} / \mathrm{z}, 702,728$, and 750 in the negative ion mode. Each $[\mathrm{M}+\mathrm{H}]^{+}$ion was subjected to CID MS-MS in the positive ion mode. In each spectrum one major product ion was observed (Fig. 5), corresponding to the loss of $155 \mathrm{amu}$ resulting from the elimination of the monomethylethanolamine phosphate head group (see Table 1).

Negative ion CID MS-MS of the $[\mathrm{M}-\mathrm{H}]^{-}$pseudomolecular ions was carried out in order to establish which fatty acids are present in each species, based on a consideration of the carboxylate anions produced. The $[\mathrm{M}-\mathrm{H}]^{-}$precursor ion at $\mathrm{m} / \mathrm{z}$ 702 yields a negative ion CID MS-MS spectrum containing ions corresponding to carboxylate anions at $\mathrm{m} / \mathrm{z} 253$ for a C16:1 fatty acid, and at $m / z, 255$ for a C16:0 fatty acid. Similarly, the precursor $[\mathrm{M}-\mathrm{H}]^{-}$ion at $m / z, 728$ yields product ions at $m / z 253(\mathrm{C} 16: 1)$ and 281 (C18:1), while the precursor with $\mathrm{m} / \mathrm{z} 750$ yields product ions at 275 and 281 , indicating it corresponds to a MMPE bearing one C18:4 and one C18:1 fatty acyl chain (Fig. 5 insert), and is thus presumably responsible for the $303 \mathrm{~nm}$-absorption maximum.

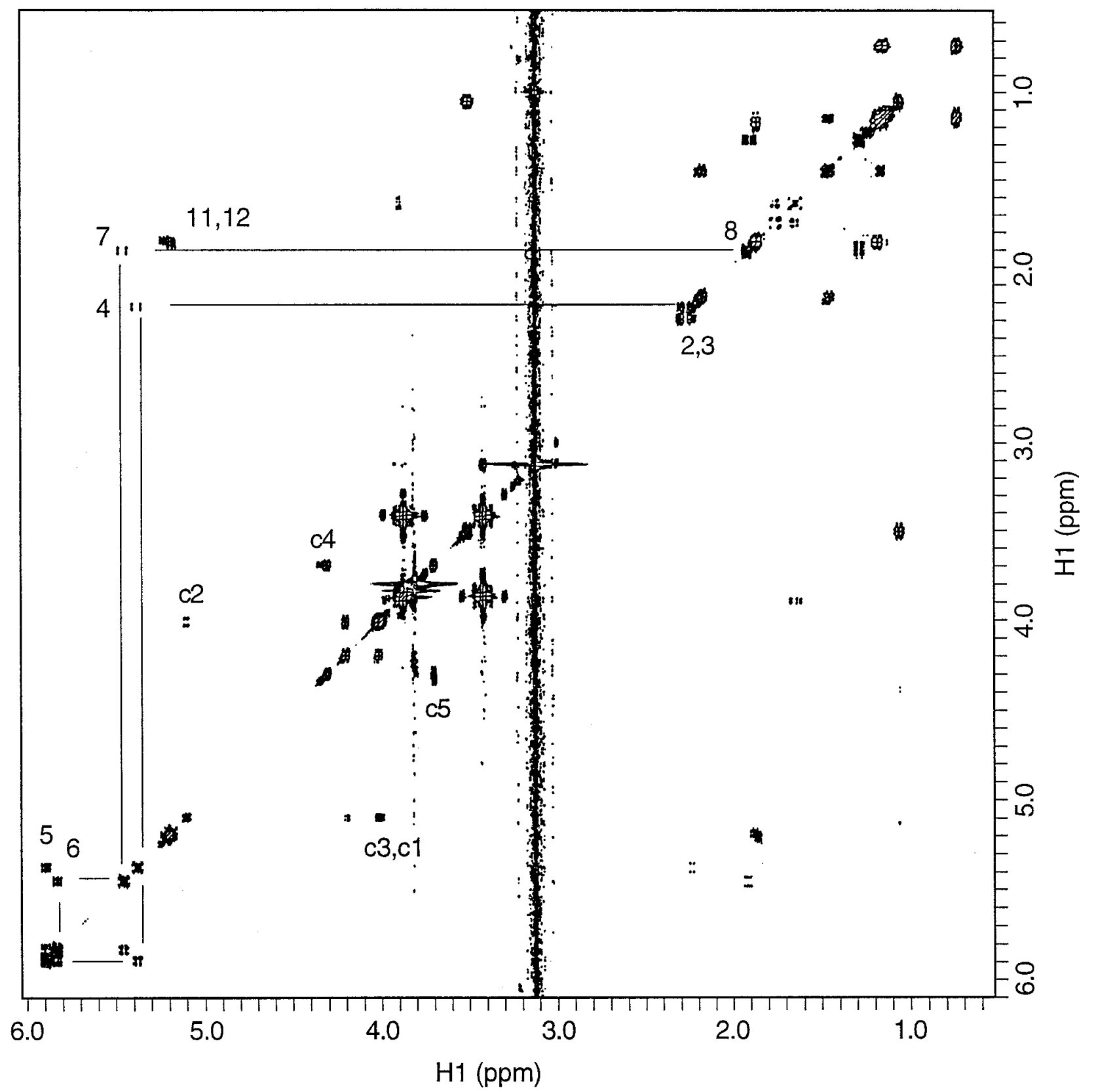

Fig. 3. Double-quantum-filtered proton-proton correlated (DQFCOSY) spectrum (600 MHz) of the $225 \mathrm{~nm}$-absorbing phosphatidylcholine (PC). Connectivity indicated corresponds to the conjugated double bond system (peaks labeled 4 to 7 ) and to the rest of the acyl chain (peaks 2,3 , and 8 to 15 ). 
The positive ion FAB-MS of the purified $225 \mathrm{~nm}$-absorbing MMPE gave a major $[\mathrm{M}+\mathrm{H}]^{+}$pseudomolecular ion at $m / z, 754$ accompanied by a thioglycerol adduction at $\mathrm{m} / \mathrm{z} 862$. In the negative ion mode, an $[\mathrm{M}-\mathrm{H}]^{-}$pseudomolecular ion for the same species was observed at $\mathrm{m} / \mathrm{z}, 752$.

In order to test for the presence of MMPE, the $[\mathrm{M}+\mathrm{H}]^{+}$ion at $m / z 754$ was subjected to CID MS-MS in the positive ion mode. One major product ion was observed (Fig. 6) at $\mathrm{m} / \mathrm{z}$ 599 , corresponding to the loss of the monomethylethanolamine phosphate head group $\left[\mathrm{M}-\mathrm{PO}_{4} \mathrm{CH}_{2} \mathrm{CH}_{2} \mathrm{~N}\left(\mathrm{CH}_{3}\right)\right]^{+}$(155 amu) as expected from MMPE.

CID MS-MS in the negative ion mode of the precursor ion at $m / z 752$ was carried out (Fig. 6 insert) in order to establish the fatty acids present. Two product ions were observed at $\mathrm{m} / \mathrm{z}$ 277 and 281, corresponding to the carboxylate anions of a $\mathrm{C} 18: 3$ and a C18:1 fatty acid.

The fraction corresponding to the $303 \mathrm{~nm}$-absorption maximum for species assumed to correspond to phosphatidylglycerols failed to give pseudomolecular ions when analyzed by positive ion mode FAB-MS in a matrix of thioglycerol, but gave intense ions at $m / z 769$ and 791 when analyzed in a matrix of $m$-NBA. These ions correspond to $[\mathrm{M}+\mathrm{H}]^{+}$and $[\mathrm{M}+\mathrm{Na}]^{+}$pseudomolecular ions for a PG species bearing a total of 36 carbon atoms and five double bonds. Positive ion mode CID analysis of each of these two pseudomolecular ions yielded spectra containing an intense fragment ion at $\mathrm{m} / \mathrm{z} 597$, which corresponds to the loss of the glycerol phosphate head group from the $[\mathrm{M}+\mathrm{H}]^{+}$ion (Fig. 7) and the loss of glycerol sodium phosphate from the $[\mathrm{M}+\mathrm{Na}]^{+}$species, together with a fragment ion at $\mathrm{m} / z 195$ for the glycerol sodium phosphate head group, demonstrating that these components do indeed correspond to PGs. In addition to the intense fragment ion at $\mathrm{m} / z 597$ in the CID mass spectrum obtained from the 769 precursor, a second, much less intense fragment ion was observed at $\mathrm{m} / \mathrm{z} .575$, which can be rationalized as arising by loss of a glycerol sodium phosphate head group from a species having a total of 34 carbons and two double bonds, presumably from one C16:1 and one C18:1 fatty acyl chain. In other words, there is evidence for the presence of a small amount of a contaminating species present in this fraction that would not give rise to a $303 \mathrm{~nm}$-absorption maximum, but that is incompletely fractionated during the chromatography.

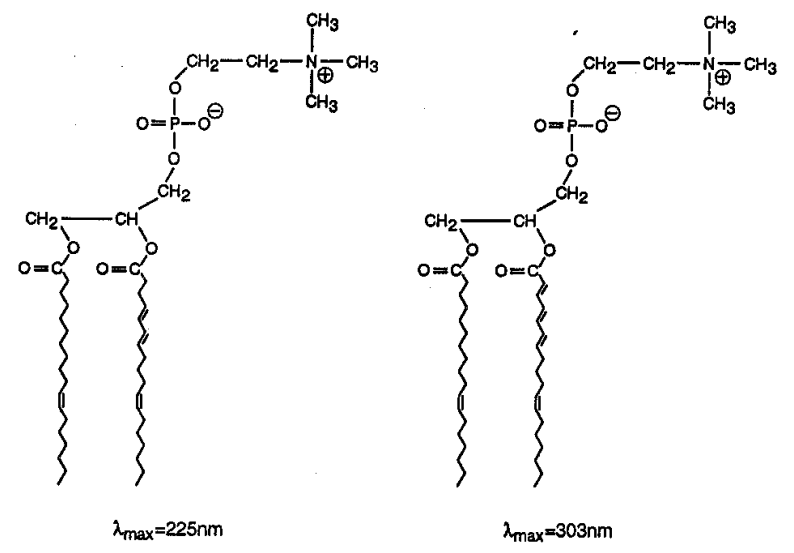

Fig. 4. Structures of $225 \mathrm{~nm}$-absorbing phosphatidylcholine (PC) and 303 nm-absorbing PC from Rhizobium leguminosarum bv. viciae.
The negative ion mode FAB-MS of this fraction, obtained in a matrix of thioglycerol, contains a pair of $[\mathrm{M}-\mathrm{H}]^{-}$pseudomolecular ions at $\mathrm{m} / \mathrm{z} 767$, corresponding to a PG species with a total of 36 carbon atoms and five double bonds, and $\mathrm{m} / z .745$, corresponding to the species having 34 carbon atoms and two double bonds. The $[\mathrm{M}-\mathrm{H}]^{-}$ions are accompanied by thioglycerol adduct ions at $m / z, 853$ and 875 . The negative ion collision spectrum obtained from the ion at $\mathrm{m} / \mathrm{z} 767$ gives ions at $\mathrm{m} / \mathrm{z}$ 275 and 281 (Fig. 7 insert), corresponding to carboxylate ions for its component fatty acids, a C18:4 $(\mathrm{m} / \mathrm{z}, 275)$ and a C18:1 $(\mathrm{m} / \mathrm{z}, 281)$ species.

The fraction eluting very close to that with the $303 \mathrm{~nm}-$ absorption maximum and having a $225 \mathrm{~nm}$-absorption maximum was also analyzed by positive ion mode FAB-MS in a matrix of $m$-NBA. This gave a series of ions at $m / z 769,771$, 773, 791, 793, and 795, the latter two being much the most intense, and corresponding to $[\mathrm{M}+\mathrm{Na}]^{+}$pseudomolecular ions for species bearing a total of 36 carbon atoms and four and three double bonds, respectively. Positive ion CID MS-MS analysis of the precursor at $\mathrm{m} / \mathrm{z} 793$ yielded one fragment ion at $\mathrm{m} / \mathrm{z} 599$ corresponding to the loss of the glycerol sodium phosphate head group from an $[\mathrm{M}+\mathrm{Na}]^{+}$ion for a PG bearing a total of 36 carbon atoms and four double bonds, together with an ion at $m / z 621$, for the loss of glycerol phosphate. In the same way, the positive ion CID MS-MS analysis of the

Table 1. Summary of fast atom bombardment-mass spectrometric data obtained from high-pressure liquid chromatography (HPLC)-purified phospholipids with structural assignments ${ }^{\mathrm{a}}$

\begin{tabular}{lllll}
\hline Fraction & $\begin{array}{l}\text { Ionization } \\
\text { mode }\end{array}$ & $\begin{array}{l}{[\mathbf{M}+\mathbf{H}]^{+}} \\
\text {or }[\mathbf{M}-\mathbf{H}]^{-}\end{array}$ & Fragments & Assignments \\
\hline A & Pos & 704 & 549 & MMPE \\
& Neg & 702 & 253,255 & C16:1, C16:0 \\
& Pos & 730 & 575 & MMPE \\
& Neg & 728 & 253,281 & C16:1, C18:1 \\
& Pos & 752 & 597 & MMPE \\
& Neg & 750 & 275,281 & C18:4, C18:1 \\
B & Pos & 754 & 599 & MMPE \\
& Neg & 752 & 277,281 & C18:3, C18:1 \\
C & Pos & 780 & 597 & PC \\
& Neg & 778 & 275,281 & C18:4, C18:1 \\
D & Pos & 782 & 184 & PC \\
& Neg & 780 & 277,281 & C18:3, C18:1 \\
& Pos & 784 & 184 & PC \\
& Pos & 758 & 184 & PC \\
E & Pos & 769 & 597 & PG \\
& Neg & 767 & 275,281 & C18:4, C18:1 \\
F & Pos & 771 & 599 & PG \\
& Neg & 769 & 277,281 & C18:3, C18:1 \\
& Pos & 773 & 601 & PG \\
& Neg & 771 & 279,281 & C18:2, C18:1 \\
\hline
\end{tabular}

${ }^{a}$ From the neutral fraction, phospholipids with a retention time on silica gel of 15 to 17 (A, B) or 34 to 40 (C, D) min were separated further on reverse phase HPLC. Reverse phase separation yielded a 303 nmabsorbing fraction with a retention time of 124 to 132 min (A) and a $225 \mathrm{~nm}$-absorbing fraction with a retention time of 135 to $152 \mathrm{~min}$ (B), or in the alternative case a $303 \mathrm{~nm}$-absorbing fraction with a retention time of 128 to $144 \mathrm{~min}(\mathrm{C})$, and a $225 \mathrm{~nm}$-absorbing fraction with a retention time of 150 to $164 \mathrm{~min}$ (D). The anionic fraction that eluted with a retention time of 8 to 9 min from silica gel was separated further on reverse phase HPLC, yielding a $303 \mathrm{~nm}$-absorbing fraction with a retention time of 38 to $42 \mathrm{~min}(\mathrm{E})$, and a $225 \mathrm{~nm}$-absorbing fraction with a retention time of 44 to $49 \mathrm{~min}(\mathrm{~F})$.

${ }^{\mathrm{b}}$ See Results for definitions of abbreviations. 
precursor ion at $m / z, 795$ yielded fragments, corresponding to the loss of the glycerol sodium phosphate head group $(\mathrm{m} / \mathrm{z}$ 601) from a PG species bearing a total of 36 carbon atoms and three double bonds, and present as its $[\mathrm{M}+\mathrm{Na}]^{+}$ion, together with a second fragment at $m / z, 623$ produced by the loss of the glycerol phosphate head group. The negative ion mass spectrum obtained in a matrix of thioglycerol contains a pair of intense $[\mathrm{M}-\mathrm{H}]^{-}$ions at $m / z, 769$ and 771 , together with thioglycerol adduct ions at $\mathrm{m} / \mathrm{z} 877$ and 879 , corresponding to PGs bearing 36 carbon atoms and a total of four and three double bonds, respectively. Negative ion CID spectra of the $[\mathrm{M}-\mathrm{H}]^{-}$ ions contain product ions corresponding to carboxylate anions of the component fatty acyl chains-the precursor ion at $\mathrm{m} / \mathrm{z}$ 769 generates such ions as $m / z 277$ (C18:3) and 281 (C18:1) (Fig. 8A), while that at $m / z 771$ yields product ions at $m / z 279$ (C18:2) and 281 (C18:1) (Fig. 8B).

nodFE from $R$. leguminosarum bv. viciae are involved in the synthesis of at least three polyunsaturated fatty acids.

In an earlier paper we described the production of $303 \mathrm{~nm}-$ absorbing phospholipids containing a C18:4 fatty acid caused by the presence of nodFE from $R$. leguminosarum bv. viciae (Geiger et al. 1994). Separation and purification of phospholipid species based on their acyl chains allows baseline sepa- ration of phospholipids bearing C18:4 (303 nm absorbance) from phospholipids bearing C18:3 (225 nm absorbance) fatty acyl moieties. Phospholipids having a nodFE-derived C18:2 (no specific absorbance, but absorbance at $205 \mathrm{~nm}$ ) fatty acyl chain are sometimes found as minor impurities in fractions containing phospholipids with a $225-\mathrm{nm}$ absorbance. Peak areas of GC analysis of fatty acyl methyl esters (Fig. 1) indicate that nodFE-induced lipid extracts from $R$. leguminosarum bv. viciae contain more $\mathrm{C} 18: 2$ than $\mathrm{C} 18: 3$ fatty acids. Chromatographic separation of the $303 \mathrm{~nm}$-absorbing from the 225 $\mathrm{nm}$-absorbing species of individual phospholipid classes (Fig. 2) and their relative molar absorptivities indicate that in each case significantly more of the $225 \mathrm{~nm}$-absorbing, C18:3 fatty acid-containing species is present than of the $303 \mathrm{~nm}-$ absorbing, C18:4 fatty acid-containing species.

\section{DISCUSSION}

\section{Three nodFE-related polyunsaturated fatty acids} are produced in $R$. leguminosarum bv. viciae.

GC-MS analysis of methanolyzed Bligh-Dyer extracts of whole cells from $R$. leguminosarum bv. viciae revealed the methyl esters of two novel nodFE-induced fatty acids with the masses 294 , corresponding to a C18:2 fatty acid, and 292, rep-

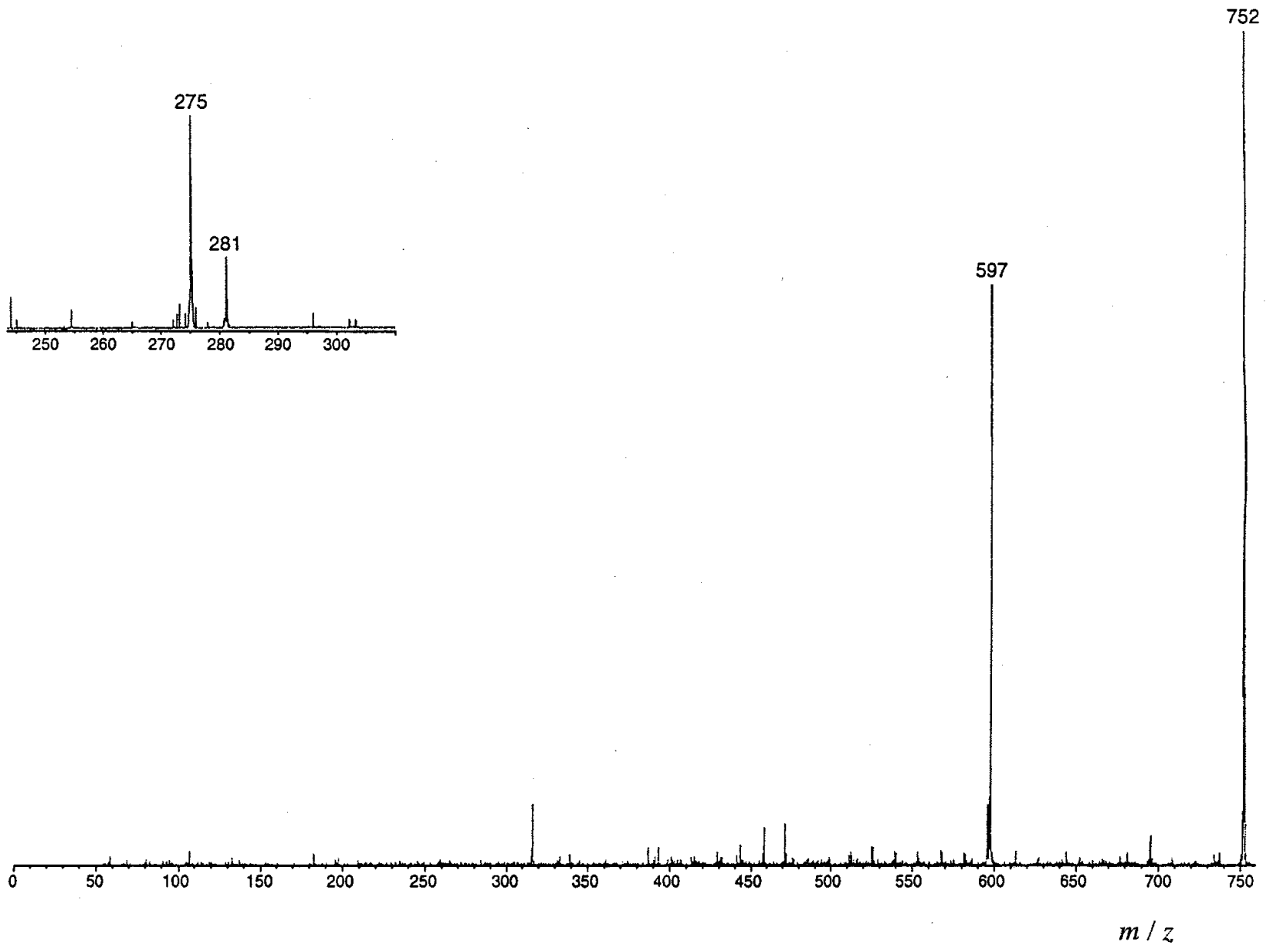

Fig. 5. Mass spectrometry of 303 nm-absorbing monomethylphosphatidylethanolamine (MMPE). Positive ion collision-induced-dissociation tandem mass spectrum of the $303 \mathrm{~nm}$-absorbing MMPE with partial negative ion collision spectrum as insert. 
resenting a C18:3 fatty acid. Authentic, chemically synthesized trans-2, trans-4, trans-6, cis-11-octadecatetraenoic acid (C18:4) methyl ester, with a mass of 290, migrates on GC with the same retention time as other major fatty acid methyl esters (data not shown) and therefore the trans-2, trans-4, trans-6, cis-11-octadecatetraenoic acid, which is formed in lesser amounts than the nodFE-dependent C18:2 or C18:3 fatty acids, escaped detection in whole-cell Bligh-Dyer extracts as its methyl ester. Diode array analysis of HPLC elution profiles of phospholipids allowed detection of either one of two nodFE-induced absorbances. If a phospholipid showed a 225-nm absorbance, it contained a C18:3 fatty acid (mass of fatty acid methyl ester $=292$; presumably trans -4 , trans -6 , cis-11-octadecatrienoic acid), and if a phospholipid showed an absorbance maximum at $303 \mathrm{~nm}$ it contained a C18:4 fatty acid, identified as trans-2, trans-4, trans-6, cis-11-octadecatetraenoic acid (mass of fatty acid methyl ester $=290)($ Geiger et al. 1994), the latter being identical to the nodFE-derived polyunsaturated fatty acid, conferring host specificity on the mitogenic LCOs of $R$. leguminosarum bv. viciae (Spaink et al. 1991). We therefore conclude that nodFE are responsible for the synthesis of three polyunsaturated fatty acids: a C18:2 fatty acid (mass of methyl ester $=294$, probably trans-6, cis11-octadecadienoic acid); a $225 \mathrm{~nm}$-absorbing C18:3 fatty acid (mass of methyl ester $=292 ;$ trans -4 , trans -6 , cis-11- octadecatrienoic acid); and the $303 \mathrm{~nm}$-absorbing C18:4 fatty acid (mass of methyl ester $=290$ ), identified previously as trans-2, trans-4, trans-6, cis-11-octadecatetraenoic acid (Fig. $9)$. It is interesting to note that when a plasmid carrying the nodFE genes of $R$. leguminosarum bv. viciae was introduced into $R$. meliloti nodFE- and nodFEG-deleted strains, LCOs with polyunsaturated $\mathrm{C} 18$ fatty acids (C18:2, C18:3, and C18:4) were detected (Demont et al. 1993). However, the C18:3 and the C18:2 fatty acyl groups found on LCOs of $R$. meliloti harboring the nodFE genes of $R$. leguminosarum bv. viciae are strikingly different from the C18:3 and the C18:2 fatty acyl groups we have found in the phospholipids of $R$. leguminosarum bv. viciae and which we describe here. The C18:3 and the C18:2 fatty acyl groups found on LCOs of $R$. meliloti harboring the nodFE genes of $R$. leguminosarum bv. viciae are described as trans-2, trans-4, cis-11-octadecatrienoic acid (absorbance maximum at $270 \mathrm{~nm}$ ) and trans-2, cis-11-octadecadienoic acid (absorbance maximum around $220 \mathrm{~nm}$ ), respectively, and are therefore both $\alpha-\beta$ unsaturated fatty acids. These latter two fatty acids have not been described in $R$. leguminosarum bv. viciae and their occurrence in $R$. meliloti might be due to the presence of an extra enoyl reductase in $R$. meliloti (Demont et al. 1993).

From the GC elution profile of methanolyzed Bligh-Dyer extracts of whole cells from Rhizobium leguminosarum we

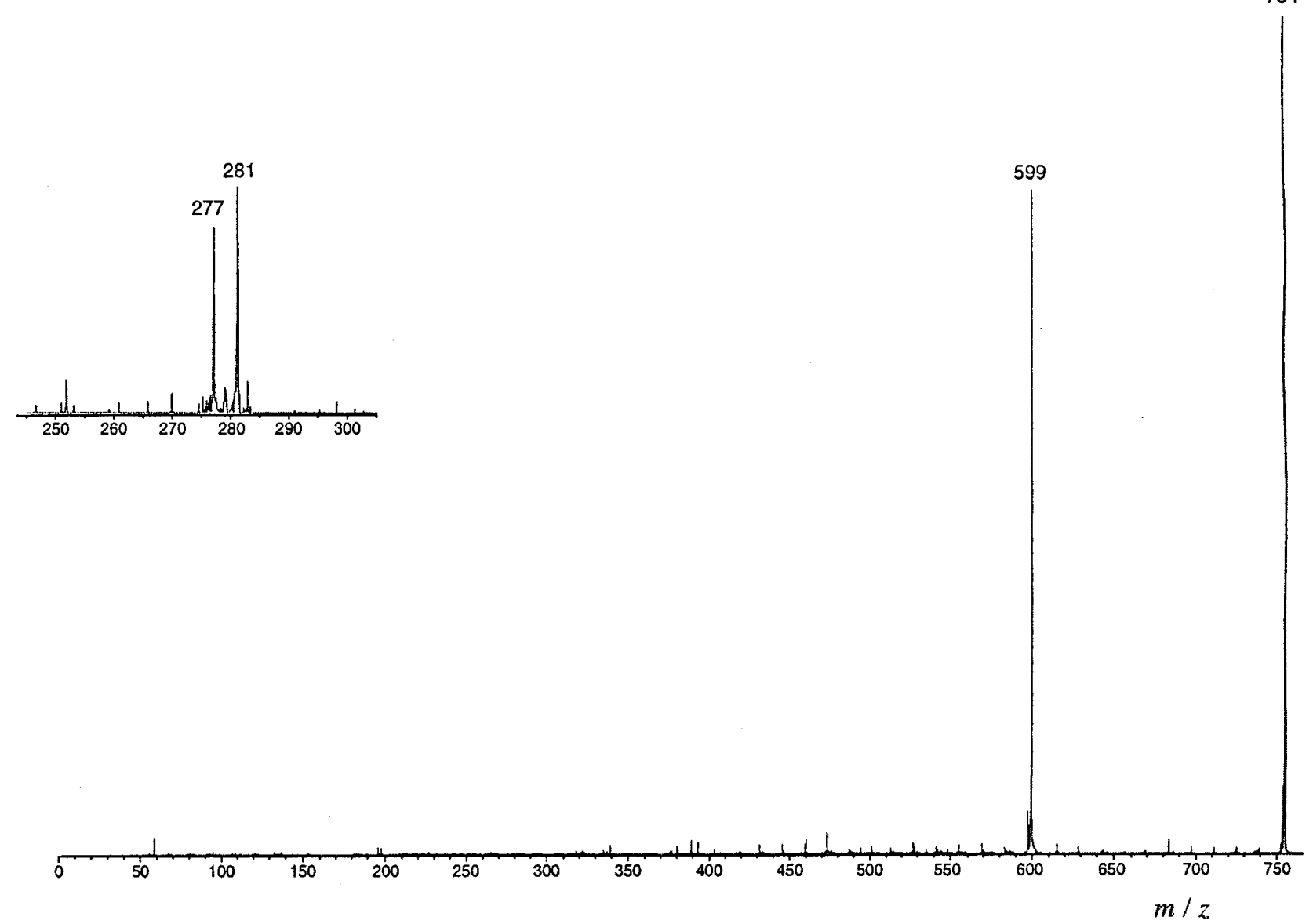

Fig. 6. Mass spectrometry of $225 \mathrm{~nm}$-absorbing monomethylphosphatidylethanolamine (MMPE). Positive ion collision-induced-dissociation tandem mass spectrum of the $225 \mathrm{~nm}$-absorbing MMPE with partial negative ion collision spectrum as insert. 
conclude that more $\mathrm{C} 18: 2$ fatty acid than $\mathrm{C} 18: 3$ fatty acid is produced. From the observation that the $225-\mathrm{nm}$ absorbance in a given phospholipid class is always higher than the $303-\mathrm{nm}$ absorbance, and considering that for a less conjugated system (C18:3) the molar extinction coefficients are lower than for a more conjugated system (C18:4), we also conclude that the C18:3 fatty acid is more abundant than the C18:4 fatty acid.

\section{Purification of phospholipids containing $n o d F E$-dependent fatty acids.}

Anionic phospholipids (PG and CL) were separated from neutral phospholipids by chromatography on DEAE-cellulose 52. Purification into classes according to head group was achieved with normal phase HPLC. Further purification by reverse phase HPLC (Spherisorb ODS-2) allows a separation on the basis of the fatty acyl residues, thereby allowing the isolation of individual phospholipid species. The following nodFE-dependent phospholipids have been purified and extensively characterized by MS and MS-MS in the positive and negative ion modes. The results allow a determination of the polar head groups (in the positive mode) as well as the identification (and for PCs the determination of the sites of attachment) of the phospholipid-linked fatty acids (in the negative mode): (i) the $303 \mathrm{~nm}$-absorbing PC contains a C18:4 at $s n-2$ position and a C18:1 fatty acid at $s n-1$ position (Fig. 4); (ii) the $225 \mathrm{~nm}$-absorbing PC contains a C18:3 at $s n-2$ position and a C18:1 fatty acid at $s n-1$ position (Fig. 4); (iii) the 303 nm-absorbing MMPE contains one C18:4 and one C18:1 fatty acid; (iv) the $225 \mathrm{~nm}$-absorbing MMPE contains one C18:3 and one C18:1 fatty acid; (v) the $303 \mathrm{~nm}$-absorbing PG contains one $\mathrm{C} 18: 4$ and one $\mathrm{C} 18: 1$ fatty acid; (vi) the $225 \mathrm{~nm}-$ absorbing PG contains one C18:3 and one C18:1 fatty acid; and (vii) as a minor impurity in the $225 \mathrm{~nm}$-absorbing PG we find a PG that contains a C18:2 and a C18:1 fatty acid.

In conclusion, NodFE are involved in the synthesis of three polyunsaturated fatty acids (C18:2, C18:3, and C18:4) and, of all the nod genes, only the nodFE genes are needed for their synthesis. All three fatty acids are incorporated into the phospholipids (amounts: C18:2 > C18:3 > C18:4) and they show a characteristic absorbance maximum at 303 (C18:4) or 225 (C18:3) nm, or show only absorbance at $206 \mathrm{~nm}$ but no specific absorbance (C18:2).

\section{Biosynthesis and acyl transfer of nodFE-dependent fatty acids.}

Surprisingly, the mitogenic, host-specific LCOs from $R$. leguminosarum bv. viciae contain only one sort of nodFEderived fatty acid, the $\alpha-\beta$ unsaturated $\mathrm{C} 18: 4$ fatty acid. Therefore, we report here for the first time on novel fatty acids synthesized by the biochemical action of NodFE but which

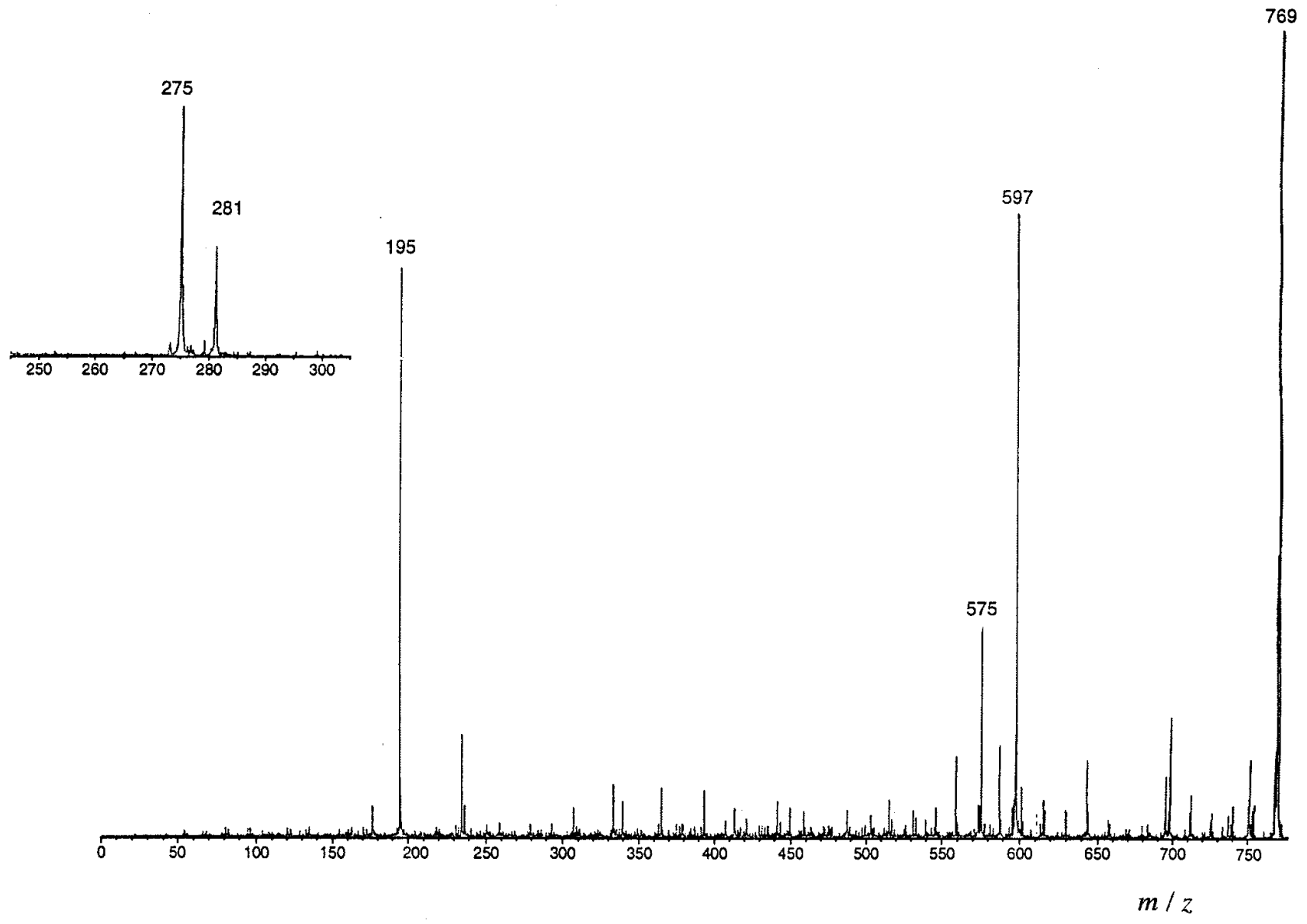

Fig. 7. Mass spectrometry of $303 \mathrm{~nm}$-absorbing phosphatidylglycerol (PG). Positive ion collision-induced-dissociation tandem mass spectrum of the $303 \mathrm{~nm}$-absorbing PG with partial negative ion collision spectrum as insert. 
are not used in LCO biosynthesis. These observations have yielded an insight into LCO biosynthesis, especially as to how the acyltransferase might work. Only the C18:4 fatty acid is selectively transferred to the LCOs. There are two possible explanations for this effect: Either (i) the acyltransferase (presumably NodA) that transfers fatty acyl residues to de- $\mathrm{N}$ acetylated chitooligomers has a high degree of selectivity for $\alpha-\beta$ unsaturated fatty acids, or (ii) the LCO acyltransferase is selective for acyl-NodF intermediates and fatty acids lacking an $\alpha-\beta$ unsaturation (C18:3 and C18:2) might not be linked to NodF. A model on the biosynthesis of the different nodFEderived fatty acids in R. leguminosarum bv. viciae (Fig. 10) explains how they can be linked to different acyl carrier proteins, either the constitutive AcpP or the nodulation protein NodF. It is currently thought that the acyl carrier protein NodF and the presumable condensing enzyme NodE modify normal fatty acid biosynthesis in such a way that when $\alpha-\beta$ unsaturated fatty acyl residues are linked to NodF they do not undergo the second reduction step of a normal fatty acid synthesis elongation cycle (Geiger et al. 1994). In the following round of fatty acid elongation an C14:2 $\alpha-\beta$ unsaturated acylNodF could be condensed either with malonyl-NodF or malonyl-AcpP, leading to the formation of C16:3 acyl-NodF and C16:3 acyl-AcpP derivatives with two trans double bonds in conjugation to the carbonyl group, respectively. The $\mathrm{C} 16: 3$ acyl-AcpP, which is not protected against the second reduction step of the fatty acid elongation cycle, would be reduced in the $\alpha-\beta$ position of the acyl residue, leading to C16:2 acyl-AcpP. As $R$. leguminosarum predominantly synthesizes fatty acids with a chain length of 18 carbons (Spaink et al. 1991), it is to be expected that the C16:2 acyl-AcpP is converted in a subsequent complete elongation cycle to the $\mathrm{C} 18: 2$ octadecadienoyl-AcpP. The C16:3 acyl-NodF, harboring two trans double bonds in conjugation to the carbonyl group, would be condensed in another round of fatty acid elongation with malonyl-NodF or malonyl-AcpP, leading to the formation of C18:4 acyl-NodF and C18:4 acyl-AcpP derivatives with three trans double bonds in conjugation to the carbonyl group, respectively. The unprotected C18:4 acyl-AcpP would be subject to a second reduction, leading to an $\alpha-\beta$ saturated $\mathrm{C} 18: 3$

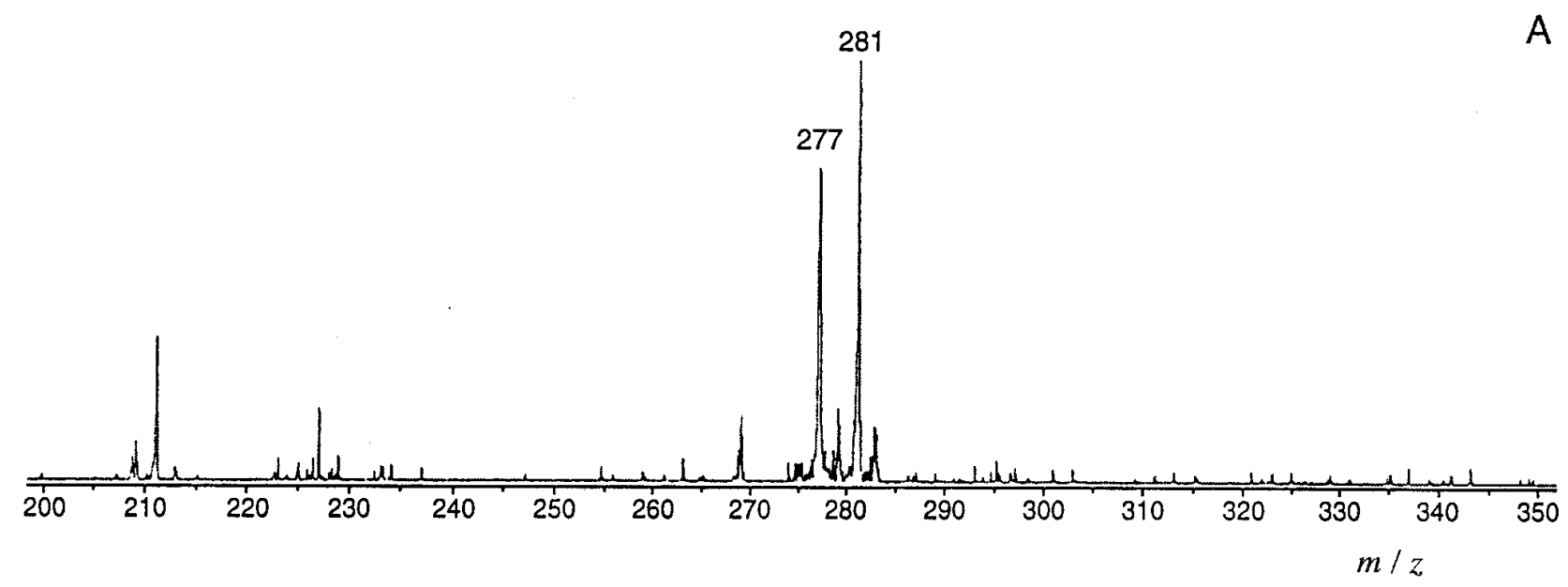

B

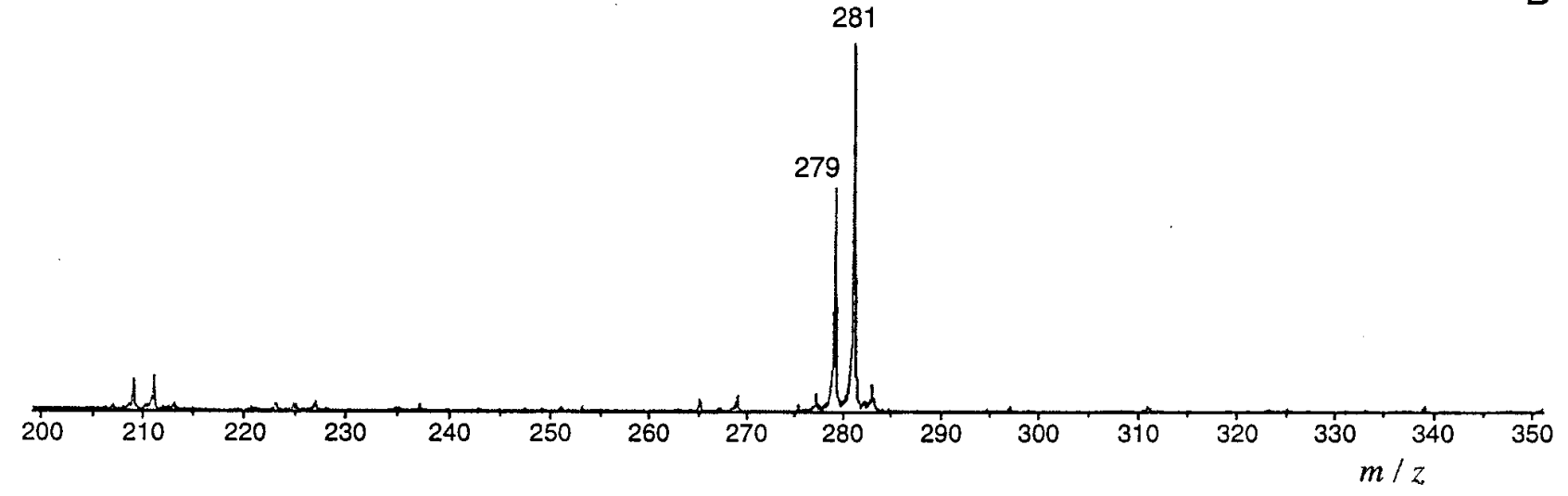

Fig. 8. Fatty acyl residues in nodFE-derived phosphatidylglycerols (PGs). Partial collision-induced-dissociation tandem mass spectra in the negative ion mode of (A) the $225 \mathrm{~nm}$-absorbing PG and (B) the C18:2 fatty acyl-containing PG. 
octadecatrienoyl-AcpP. The C18:4 octadecatetraenoyl-NodF remains unaltered until acyl transfer reactions occur. Therefore, of the nodFE-derived fatty acids only the C18:4 would be linked to NodF and transferred to LCOs and phospholipids, whereas the others (C18:3 and C18:2) would be linked to the constitutive acyl carrier protein AcpP and would not be transferred to LCOs, but only to phospholipids (Fig. 10). Such a mechanism would lead to the introduction of only the C18:4 fatty acid into LCOs and to a significant discrimination against the other nodFE-derived polyunsaturated fatty acids, the $\mathrm{C} 18: 3$ and the $\mathrm{C} 18: 2$.

\section{MATERIALS AND METHODS}

Bacterial strains, plasmids, and growth conditions.

Strains and plasmids are listed in Table 2. Broad host range plasmids were mobilized from Escherichia coli K12 strain KMBL1164 to R. leguminosarum with pRK2013 as a helper plasmid (Ditta et al. 1980) as previously described (Spaink et al. 1987).

Cultures of $R$. leguminosarum were grown on medium $\mathrm{B}$ (van Brussel et al. 1977) at $30^{\circ} \mathrm{C}$ on a gyratory shaker. If strains harbored broad host range plasmids, $0.5 \mathrm{mg}$ of streptomycin per $\mathrm{ml}$ was added to maintain IncQ plasmids and 2 $\mu \mathrm{g}$ of tetracycline per $\mathrm{ml}$ was added to maintain IncP plasmids. For induction, naringenin $(1.5 \mu \mathrm{M}$ final concentration) was added at a cell density of $5 \times 10^{7}$ per ml. Cells were usually harvested after 3 generations of further growth.

\section{Extraction of lipids.}

Lipids were extracted by a modified Bligh and Dyer (Bligh and Dyer 1959) procedure. Wet cell paste was made up to 1 volume with water, and to the suspension 3.75 volumes of methanol/chloroform $(2: 1, \mathrm{vol} / \mathrm{vol})$ was added. The mixture

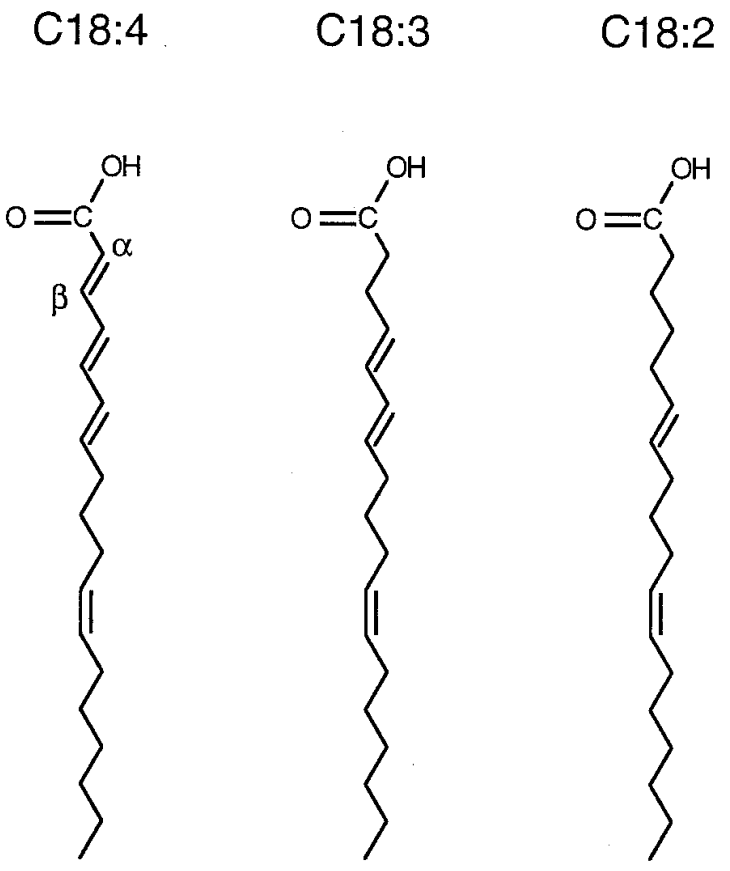

Fig. 9. Proposed structures for nodFE-derived fatty acids in Rhizobium leguminosarum bv. viciae. was gently stirred for $1 \mathrm{~h}$ at room temperature. After centrifugation, the supernatant extract was decanted into a glass tube and the pellet was reextracted with 4.75 volumes methanol/ chloroform/water $(2: 1: 0.8, \mathrm{vol} / \mathrm{vol})$ and centrifuged. To the combined supernatant extracts were added 2.5 volumes each of chloroform and water, and the mixture was centrifuged. The lower chloroform phase was withdrawn and brought to dryness in a rotary evaporator. The lipid residue was immediately redissolved in methanol/chloroform (1:1) and was stored under nitrogen at $-20^{\circ} \mathrm{C}$.

\section{Methanolysis of lipids.}

Dried lipid extracts were treated with $0.5 \mathrm{ml}$ of hydrochloric methanol $(0.6 \mathrm{~N} \mathrm{HCl}$ in methanol) in sealed Teflon tubes under nitrogen at $65^{\circ} \mathrm{C}$ for $15 \mathrm{~h}$. After addition of $0.5 \mathrm{ml}$ of water the methyl esters were extracted twice with two volumes of $0.5 \mathrm{ml}$ of methylene chloride.

\section{Analysis of fatty acid methyl esters with GC and GC linked to MS.}

The combined methylene chloride extracts were dried down and taken up in a total volume of $50 \mu \mathrm{l}$ of methylene chloride. Usually, $1 \mu \mathrm{l}$ of sample was injected and analysis was performed on a $60-\mathrm{m} \mathrm{DB}-1$ column ( $\mathrm{J} \& \mathrm{~W})$ with the following temperature program: the initial temperature of $75^{\circ} \mathrm{C}$ was raised at the rate of $10^{\circ}$ per min and was held constant after the final temperature of $250^{\circ} \mathrm{C}$ was reached. The injector temperature was $250^{\circ} \mathrm{C}$.

For quantification of fatty acid methyl esters a flame ionization detector (at $250^{\circ} \mathrm{C}$ ) was used with a Hewlett-Packard 5890 instrument fitted with the DB-1 column.

When GC-MS was performed, a Hewlett-Packard 5995 instrument fitted with the DB-1 column was coupled to a HP 300 data system. MS temperatures were $300^{\circ} \mathrm{C}$ for the transfer line, $200^{\circ} \mathrm{C}$ for the ion source, and $230^{\circ} \mathrm{C}$ for the analyzer. Data were acquired in the electron impact mode $(70 \mathrm{eV})$. The scanning range was 50 to $650 \mathrm{~m} / \mathrm{z}$ at $1 \mathrm{~s}$ per decade.

\section{Purification of phospholipids.}

In order to obtain enough material to allow NMR spectroscopy on individual phospholipid species, 70 liters of rhizobial culture was grown to obtain $655 \mathrm{~g}$ of wet cells of naringenininduced $R$. leguminosarum LPR5045.pMP280.pMP1255. Bligh-Dyer extraction yielded about $4.5 \mathrm{~g}$ of total lipids.

A crude separation of neutral and anionic phospholipids was achieved by chromatography on DEAE-cellulose (DE-52, Whatman) (Kates 1986). The sample was applied as a solution in $20 \mathrm{ml}$ of chloroform (4.0 g of total lipids) to a $200-\mathrm{ml}$ column of DEAE 52-cellulose in its acetate form, which had been equilibrated with chloroform. The column was then sequentially eluted with the following solvents: 5 volumes of chloroform, 9 volumes of chloroform-methanol (9:1, vol/vol), 5 volumes of chloroform-methanol $(1: 1, \mathrm{vol} / \mathrm{vol})$, and $10 \mathrm{vol}-$ umes of chloroform-methanol (4:1, vol/vol) containing $50 \mathrm{mM}$ ammonium acetate. The individual fractions were brought to dryness in a rotary evaporator and they were immediately dissolved in methanol/chloroform $(1: 1, \mathrm{vol} / \mathrm{vol})$ and stored under nitrogen at $-20^{\circ} \mathrm{C}$.

All major phospholipid classes were separated by normalphase silica gel HPLC (Patton and Robbins 1990), either on an analytical Hypersil column $4.6 \times 160$ mm (Shandon, Pitts- 
burgh, PA) with a flow rate of $1 \mathrm{ml}$ per min, or on a Hyperprep 120 Silica $12 \mathrm{U}$ column $4.6 \times 250 \mathrm{~mm}$ (Alltech, Deerfield, IL) with a flow rate of $2 \mathrm{ml}$ per min. The mobile phase consisted of hexane/2-propanol/ethanol/25 $\mathrm{mM}$ potassium phosphate (pH 7.0)/acetic acid (485:376:100:56:0.275, vol/ vol). Diode array spectroscopic detection was performed with a Pharmacia RSD 2140 optical unit.

The purified phospholipid classes were separated into molecular species on a $4 \times 250 \mathrm{~mm}$ Superpac Spherisorb ODS-2 column (Pharmacia) (Patton et al. 1982). They were eluted with methanol/water/acetonitrile (90.5:7:2.5, vol/vol) containing 20 $\mathrm{mM}$ choline chloride at a flow rate of $0.5 \mathrm{ml}$ per min.
Table 2. Bacterial strains and plasmids

\begin{tabular}{ccc}
\hline Strain or plasmid & $\begin{array}{c}\text { Relevant characteristics } \\
\text { Rhizobium leguminosarum } \\
\text { LPR5045 }\end{array}$ & Source or reference \\
$\begin{array}{c}\text { folii } \text { Rif }^{\mathrm{r}} \text { cured of Sym } \\
\text { plasmid } \\
\text { LPR5045 with Sym plas- } \\
\text { mid pRL1JI }\end{array}$ & Zaat et al. 1987 et al. 1987 \\
$\begin{array}{c}\text { RBL5560 } \\
\text { pMP280 }\end{array}$ & $\begin{array}{c}\text { IncP carrying pr.nodD- } \\
\text { nodD }\end{array}$ & Spaink et al. 1987 \\
pMP604 & $\begin{array}{c}\text { IncP carrying FITA-type } \\
\text { nodD604 }\end{array}$ & Spaink et al. 1989 \\
pMP1255 & IncQ carrying nodFE & Geiger et al. 1991 \\
\hline
\end{tabular}

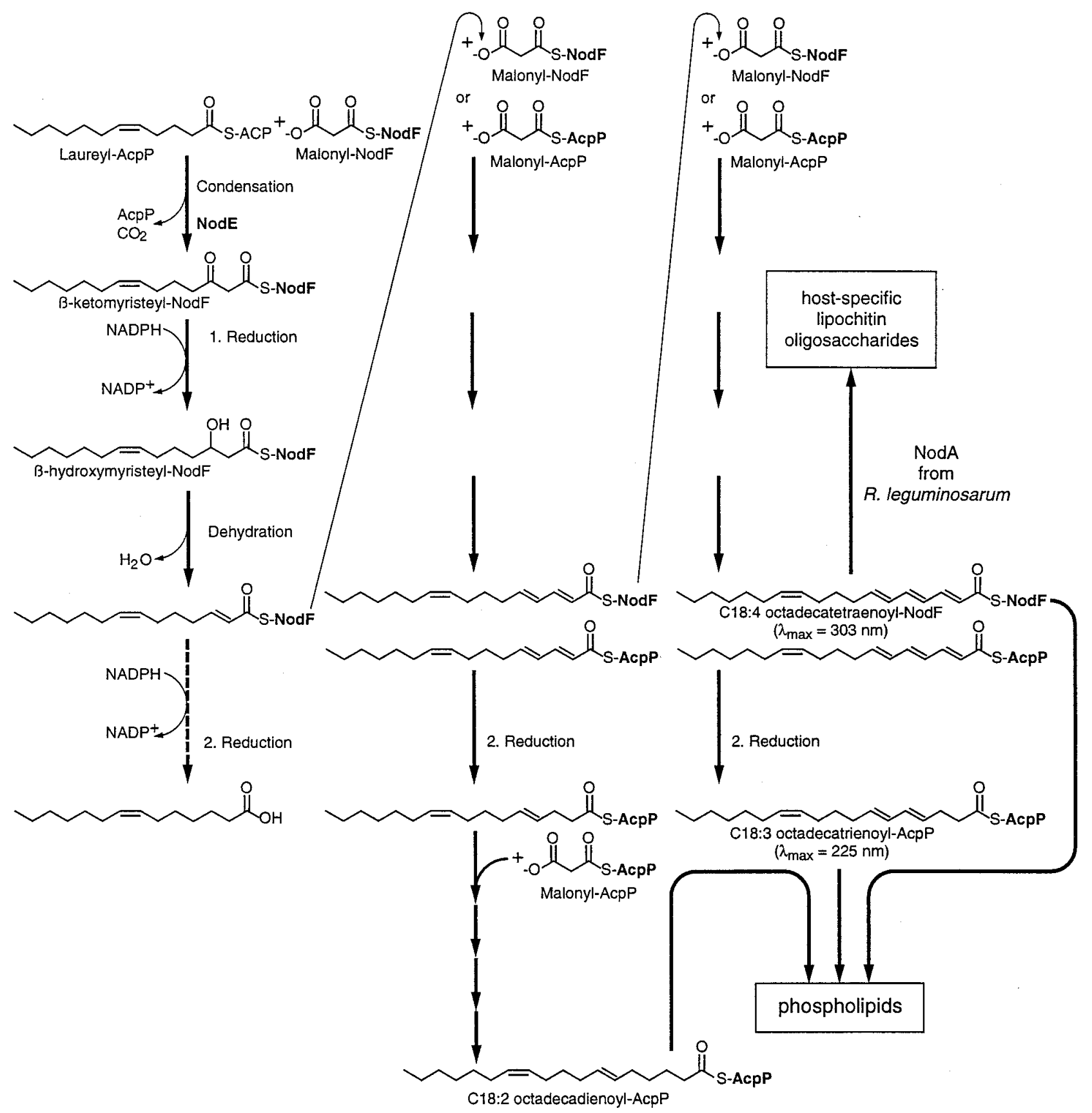

Fig. 10. Model for the biosynthesis and acyl transfer of the different nodFE-derived fatty acids. 
MS.

Positive and negative ion mode mass spectra were obtained from the purified $303 \mathrm{~nm}$ - and $225 \mathrm{~nm}$-absorbing phospholipids. Samples redissolved in chloroform/methanol (1:1, vol/ vol) were analyzed by loading 1 to $3 \mu \mathrm{l}$ of sample solution into a matrix of monothioglycerol (positive ion mode) or $m e t a$-nitrobenzyl alcohol ( $m$-NBA) (negative ion mode). Mass spectra were obtained with MS1 of a JEOL JMS-SX/SX102A tandem mass spectrometer operated at $10 \mathrm{kV}$ accelerating voltage. The FAB gun was operated at $6 \mathrm{kV}$, with an emission current of $10 \mathrm{~mA}$, and with xenon as the bombarding gas. Spectra were scanned at a speed of $30 \mathrm{~s}$ for the full mass range specified by the accelerating voltage used, and were recorded and averaged with JEOL COMPLEMENT software run on a Hewlett-Packard 9000 series data system. Tandem mass spectra were obtained from the same samples following CID in the third field free region, with the same instrument in its 4-sector mode under similar conditions, and with helium as the collision gas at a pressure sufficient to reduce the parent ion to one third of its original intensity.

\section{${ }^{1} \mathrm{H}$ NMR analysis.}

The PC sample with an absorption maximum at $225 \mathrm{~nm}$ $\left(E_{225}=32 / \mathrm{ml}\right)$ was dissolved in $0.6 \mathrm{ml}$ of $\mathrm{CD}_{3} \mathrm{OD} / \mathrm{CDCl}_{3}(1: 5$, $\mathrm{vol} / \mathrm{vol})$. Spectra were acquired on a Bruker AMX600 at $25^{\circ} \mathrm{C}$. Two-dimensional DQF-COSY experiments (Piantini et al. 1982) were performed in phase-sensitive mode by the TPPI method (Marion and Wüthrich 1983).

\section{ACKNOWLEDGMENTS}

This work was funded in part by the European Communities BIOTECH Programme 1993-1996, as part of the Project of Technical Priority, Contract No. BIO2 CT93 0400 (to B.J.J.L.), and The Netherlands Organization for Scientific Research (J.E.T.-O. and H.P.S.).

\section{LITERATURE CITED}

Atkinson, E. M., Palcic, M. M., Hindsgaul, O., and Long, S. R. 1994. Biosynthesis of Rhizobium meliloti lipooligosaccharide Nod factors: NodA is required for an $N$-acyltransferase activity. Proc. Natl. Acad. Sci. USA 91:8418-8422.

Bligh, E. G., and Dyer, W. J. 1959. A rapid method of total lipid extraction and purification. Can. J. Biochem. Physiol. 37:911-917.

Debellé, F., Plazanet, C., Roche, P., Pujol, C., Savagnac, A., Rosenberg, C., Promé, J. C., and Dénarié, J. 1996. The NodA proteins of Rhizobium meliloti and Rhizobium tropici specify the $N$-acylation of Nod factors by different fatty acids. Mol. Microbiol. 22:303-314.

Demont, N., Debellé, F., Aurelle, H., Dénarié, J., and Promé, J. C. 1993. Role of the Rhizobium meliloti nodF and nodE genes in the biosynthesis of lipo-oligosaccharidic nodulation factors. J. Biol. Chem. 268:20134-20142.

Ditta, G., Stanfield, S., Corbin, D., and Helinski, D. R. 1980. Broad host-range DNA cloning system for gram-negative bacteria: Construction of a gene bank of Rhizobium meliloti. Proc. Natl. Acad. Sci. USA 77:7347-7351.

Fukuda, M., Dell, A., Oates, J. E., Wu, P., Klock, J. C., and Fukuda, M. 1985. Structure of glycosphingolipids isolated from human granulocytes. J. Biol. Chem. 260:1067-1082.

Geiger, O., Spaink, H. P., and Kennedy, E. P. 1991. Isolation of the Rhizobium leguminosarum NodF Nodulation Protein: NodF carries a 4'-phosphopantetheine prosthetic group. J. Bacteriol. 173:28722878.

Geiger, O., Thomas-Oates, J. E., Glushka, J., Spaink, H. P., and Lugtenberg, B. J. J. 1994. Phospholipids of Rhizobium contain nodE-determined highly unsaturated fatty acid moieties. J. Biol. Chem. 269:11090-11097.
Geremia, R. A., Mergaert, P., Geelen, D., van Montagu, M., and Holsters, M. 1994. The NodC protein of Azorhizobium caulinodans is an $N$-acetylglucosaminyltransferase. Proc. Natl. Acad. Sci. USA 91: 2669-2673.

Hiyashi, A., Matsubara, T., Morita, M., Kinoshita, T., and Nakamura, T. 1989. Structural analysis of choline phospholipids by fast atom bombardment mass spectrometry and tandem mass spectrometry. J. Biochem. (Tokyo) 106:264-269.

Huang, Z.-H., Gage, D. A., and Sweeley, C. C. 1992. Characterization of diacylglycerolphosphocholine molecular species by FAB-CADMS/MS: A general method not sensitive to the nature of the fatty acyl groups. J. Am Soc. Mass Spectrom. 3:71-78.

John, M., Röhrig, H., Schmidt, J., Wieneke, U., and Schell, J. 1993. Rhizobium NodB protein involved in nodulation signal synthesis is a chitooligosaccharide deacetylase. Proc. Natl. Acad. Sci. USA 90:625-629.

Kamst, E., van der Drift, K. M. G. M., Thomas-Oates, J. E., Lugtenberg, B. J. J., and Spaink, H. P. 1995. Mass spectrometric analysis of chitin oligosaccharides produced by Rhizobium NodC protein in Escherichia coli. J. Bacteriol. 177:6282-6285.

Kates, M. 1986. Techniques of Lipidology. 2nd ed. Elsevier Science Publishers, Amsterdam.

Marion, D., and Wüthrich, K. 1983. Application of phase sensitive two-dimensional correlated spectroscopy (COSY) for measurements of $1 \mathrm{H}-1 \mathrm{H}$ spin-spin coupling constants in proteins. Biochem. Biophys. Res. Commun. 113:967-974.

Patton, G. M., Fasulo, J. M.,, and Robbins, S. J. 1982. Separation of phospholipids and individual molecular species of phospholipids by high-performance liquid chromatography. J. Lipid Res. 23:190-196.

Patton, G. M., and Robbins, S. J. 1990. Extraction of phospholipids and analysis of phospholipid molecular species. Methods Enzymol. 187:195-215.

Piantini, U., Sorensen, O., and Ernst, R. R. 1982. Multiple quantum filters for elucidating NMR coupling networks. J. Am. Chem. Soc. 104:6800-6801.

Ritsema, T., Wijfjes, A. H. M., Lugtenberg, B. J. J., and Spaink, H. P. 1996. Rhizobium nodulation protein NodA is a host-specific determinant of the transfer of fatty acids in Nod factor biosynthesis. Mol. Gen. Genet. 251:44-51.

Roche, P., Maillet, F., Plazanet, C., Debellé, F., Ferro, M., Truchet, G., Promé, J.-C., and Dénarié, J. 1996. The common nodABC genes of Rhizobium meliloti are host-range determinants. Proc. Natl. Acad. Sci. USA 93:15305-15310.

Röhrig, H., Schmidt, J., Wieneke, U., Kondorosi, E., Barlier, I., Schell, J., and John, M. 1994. Biosynthesis of lipooligosaccharide nodulation factors: Rhizobium NodA protein is involved in $\mathrm{N}$ acylation of the chitooligosaccharide backbone. Proc. Natl. Acad. Sci. USA 91:3122-3126.

Spaink, H. P., Okker, R. J. H., Wijffelman, C. A., Pees, E., and Lugtenberg, B. J. J. 1987. Promoters in the nodulation region of the Rhizobium leguminosarum sym plasmid pRL1JI. Plant Mol. Biol. 9:27-37.

Spaink, H. P., Sheeley, D. M., van Brussel, A. A. N., Glushka, J., York, W. S., Tak, T., Geiger, O., Kennedy, E. P., Reinhold, V. N., and Lugtenberg, B. J. J. 1991. A novel highly unsaturated fatty acid moiety of lipo-oligosaccharide signals determines host specificity of Rhizobium. Nature (London) 354:125-130.

Spaink, H. P., Wijffelman, C. A., Okker, R. J. H., and Lugtenberg, B. J. J. 1989. Localization of functional regions of the Rhizobium nodD product using hybrid nodD genes. Plant Mol. Biol. 12:59-73.

Spaink, H. P., Wijffelman, C. A., Pees, E., Okker, R. J. H., and Lugtenberg, B. J. J. 1987. Rhizobium nodulation gene nodD as a determinant of host specificity. Nature (London) 328:337-340.

van Brussel, A. A. N., Bakhuizen, R., van Spronsen, P. C., Spaink, H. P., Tak, T., Lugtenberg, B. J. J., and Kijne, J. W. 1992. Induction of pre-infection thread structures in the leguminous host plant by mitogenic lipo-oligosaccharides of Rhizobium. Science 257:70-72.

van Brussel, A. A. N., Planqué, K., and Quispel, A. 1977. The wall of Rhizobium leguminosarum in bacteroid and free-living forms. J. Gen. Microbiol. 101:51-56.

Zaat, S. A. J., Wijffelman, C. A., Spaink, H. P., van Brussel, A. A. N., Okker, R. J. H., and Lugtenberg, B. J. J. 1987. Induction of the nodA promoter of Rhizobium leguminosarum Sym plasmid pRL1JI by plant flavanones and flavones. J. Bacteriol. 169:198-204. 